\title{
FUGA DE DEMANDA EN EL SECTOR COMERCIAL DE POPAYÁN, COLOMBIA: UNA APROXIMACIÓN CON MODELOS LOGIT' ${ }^{1}$
}

\author{
Por: Andrés Mauricio Gómez Sánchez²
}

\section{RESUMEN}

El objetivo de este estudio es determinar los motivos por los cuales las familias de Popayán no compran bienes y servicios en el sector comercial local y lo hacen en otros municipios o ciudades. Para lograrlo se realiza un muestreo incidental y se implementa un análisis con modelos estocásticos de variable discreta logística. Entre otros resultados, el estudio muestra que para la población encuestada son las mujeres quienes compran con más frecuencia que los hombres por fuera de la ciudad artículos como ropa, zapatos y accesorios. Adicionalmente, se encuentra que un factor determinante es la variedad, seguida por los precios, aunque esto depende del estrato al que pertenezcan. Finalmente, se concluye que el comercio payanes debe mejorar en aspectos como la atención al público, horarios de atención, entre otros.

Palabras claves: Sector Comercial, Demanda, Modelos Logit.

JEL: C25, D12, M00.

1. Este documento es un resumen modificado de la investigación denominada "Determinación de los Hábitos de no Consumo en Bienes y Servicios por Parte de las Familias en el Comercio de Popayán” realizada en el segundo semestre de 2013 con financiación de la Cámara de Comercio del Cauca.

2 Magíster en Economía Aplicada, Universidad del Valle, Cali, Colombia. Docente Titular, Departamento de Economía, Universidad del Cauca, Popayán, Colombia. Correo electrónico: amgomez@ unicauca.edu.co.

Artículo recibido: 6 de febrero de 2015 .

Aprobación definitiva: 24 de mayo de 2015. 


\title{
LEAK DEMAND IN THE COMMERCIAL SECTOR POPAYÁN, COLOMBIA: AN APPROACH MODELS LOGIT
}

\author{
By: Andrés Mauricio Gómez Sánchez
}

\begin{abstract}
The aim of this study is to determine the reasons why families of Popayan not buy goods and services in the local business sector and do so in other municipalities or cities. To achieve an incidental sampling and analysis is performed with discrete stochastic models logistic variable is implemented. Among other results, the study shows that the surveyed population is women who buy more frequently than men for out of town items such as clothing, shoes and accessories. Additionally, we find that a factor is the variety, followed by the prices, although this depends on the stratum to which they belong. Finally, it is concluded that the commercial sector must improve in areas such as customer service, hours of operation, among others.
\end{abstract}

Key words: Commercial Sector, Demand, Logit Models.

JEL: C25, D12, M00. 


\title{
VAZAMENTO DEMANDA NO SETOR COMERCIAL POPAYÁN, COLOMBIA: AN MODELOS DE ABORDAGEM LOGIT
}

\author{
Por: Andrés Mauricio Gómez Sánchez
}

\section{RESUMO}

O objetivo deste estudo é determinar as razões pelas quais famílias de Popayan não compram produtos e serviços no sector empresarial local e fazê-lo em outros municípios ou cidades. Para conseguir uma amostragem incidental e análise é realizada com modelos estocásticos discretos variável logística é implementado. Entre outros resultados, o estudo mostra que a população pesquisada são as mulheres que compram mais freqüentemente do que os homens para fora da cidade itens como roupas, sapatos e acessórios. Além disso, descobrimos que um factor é a variedade, seguido pelos preços, embora isto dependa do estrato a que pertencem. Por fim, concluímos que Payanes comércio deve melhorar em áreas como atendimento ao cliente, horário de funcionamento, entre outros.

Palavras-Chave: Setor Comercial, Demanda, Modelos Logit

Classificação JEL: C25, D12, M00. 


\section{INTRODUCCIÓN}

Uno de los sectores sobre los cuales, actualmente, se basa la economía del departamento del Cauca es el sector comercial, al lado del sector servicios, y el agropecuario. En Popayán, se concentra gran parte de la dinámica comercial departamental, no solo por ser su capital sino, por condensar aproximadamente el $20 \%$ de la población y generar el 18,23\% del empleo (Observatorio Regional del Mercado de Trabajo, ORMET, 2013: 40).

Si bien es cierto, este sector ocupa un importante renglón en la economía local, su aporte al nivel de actividad económica se ve afectado por las compras que realizan las familias que residen en Popayán a otras ciudades. En efecto, una alta gama de bienes y, también, diversos servicios son adquiridos en municipios o capitales cercanas por la facilidad de desplazamiento, y en otros casos en ciudades o regiones más distantes a través de la tecnología (internet, tarjetas débito, crédito, entre otras). Así las cosas, el sector comercial local pierde una gran cantidad de ingreso por concepto de ventas al año y reduce la capacidad de expansión de la economía local, redundando en pérdidas de valor agregado, productividad y empleo, factores claves que se requiere urgentemente fortalecer y expandir, pues la ciudad presenta uno de los mayores índices de desempleo, en el último lustro, del país (19\% en promedio en el último lustro), solamente superado por Quibdó.

En este orden de ideas, cobra relevancia determinar cuáles factores influyen en la decisión de no comprar por parte de las familias que residen en esta capital, e identificar un perfil del consumidor que compra por fuera, para que a mediano y largo plazo se pueda implementar estrategias, políticas, planes, programas o proyectos que retengan la "fuga de demanda" hacia otras latitudes y que permitan de paso mejorar y fortalecer la oferta sectorial de cara a la competencia no solo local sino externa.

Para lograrlo se implementó una encuesta aleatoria con su respectivo análisis estadístico y se complementó con la estimación de modelos logísticos que permiten determinar, no solo las probabilidades de consumo foráneo en las familias payanesas, sino también, la construcción de un perfil del demandante.

Así las cosas, este documento consta de seis partes, donde la primera es esta introducción. A continuación, se relaciona de manera teórica la demanda y el comportamiento de los consumidores, y de paso se referencian algunos estudios aplicados tanto a nivel nacional como internacional frente a hábitos de compra. Seguidamente se muestran de manera descriptiva los resultados de la encuesta, y se muestra un panorama general del sector comercial payanes comparado con el caleño para luego analizar los resultados de los modelos logísticos. Finalmente, se realizan algunas conclusiones y recomendaciones.

\section{Demanda de los Consumidores y Casos Aplicados}

\subsection{Conceptos desde la Economía Neoclásica}

La demanda es un comportamiento de los consumidores que muestra la cantidad de bienes y servicios que pueden ser adquiridos a los diferentes precios del 
mercado, para poder satisfacer una necesidad o un deseo por periodo de tiempo. Esta va a determinar la asignación de los recursos productivos o, lo que es lo mismo, qué productos se deben producir y en qué cantidades.

En la visión neoclásica de la demanda, de acuerdo a Varian (2000: 91) a nivel teórico, los consumidores demandan bienes y servicios compaginando sus gustos y preferencias (representadas por curvas de indiferencias) con sus niveles de ingreso y precios (representados por la restricción presupuestaria), a través de igualación de la tasa a la que desean intercambiar bienes y servicios (tasa marginal de sustitución) con la tasa a la que realmente pueden hacerlo a precios de mercado (tasa marginal de sustitución de mercado). Este proceso, conocido como problema primal del consumidor, en términos generales, dice que los demandantes maximizan sus niveles de utilidad o satisfacción teniendo en cuenta sus niveles de ingreso y los precios de mercado.

Siguiendo a Nicholson $(2000,99)$, cuando se modifican los precios surge el efecto sustitución e ingreso. Esto no es otra cosa que la sustitución de bienes caros por baratos que realiza el consumidor manteniendo su satisfacción inicial constante, lo que obliga a que la modificación en su ingreso real debida al cambio de precios, no sea tenida en cuenta. A continuación surge el efecto ingreso, el cual muestra el nuevo grado de utilidad o satisfacción alcanzado por la modificación en el consumo de bienes, cuando el consumidor tiene en cuenta ahora la variación en su ingreso real, a los nuevos precios relativos. Para las curvas de demanda Marshallianas, si el efecto ingreso se refuerza con el sustitución se estará en el caso de los bienes normales; si el efecto sustitución tiene un sentido contrario al ingreso, pero el primero lo supera, será este el caso de los bienes inferiores, y finalmente si no logra superarlo, los bienes serán extremadamente inferiores, caso conocido como la paradoja de Giffen. Toda esta dinámica se representa a través de la ecuación de Slutsky (Varian, 2000: 156).

Para el caso de las demandas Marshallianas bien comportadas, se evidencia que existe una relación inversa entre precios y cantidades, a lo que se le denomina "ley de demanda". Por tanto a mayores precios, la cantidad demandada debe ser menor y a menores precios mayor cantidades demandadas. Esto conlleva a que la pendiente de la curva de demanda sea negativa ${ }^{3}$. La demanda tiene varios determinantes distintos al precio de venta, algunos de ellos son: el ingreso disponible de los compradores, los precios de otros bienes y servicios (que pueden ser complementarios o sustitutos); la distribución del ingreso de la sociedad entre las diferentes personas y clases, factores de tradición, culturales, institucionales, ideológicos, políticos, que los economistas los han denominado como gustos y el número de demandantes.

Un concepto muy relacionado con la demanda, es el concepto de elasticidad precio de la demanda. Ella muestra el grado de sensibilidad que experimenta la

3. De acuerdo a Fernández de Castro y Tugores (1998:81) existe la posibilidad que la demanda tenga pendiente positiva (bien Giffen,), el cual es un caso considerado como una curiosidad teórica antes que un comportamiento observable en la realidad. En general, todas las demandas guardan una relación inversa entre precios y cantidades. 
cantidad demandada de un bien o servicio cuando se modifica su propio precio, manteniendo todas las demás variables de las cuales depende la demanda, sin variación. Siguiendo a Nicholson (2000:179), dicha elasticidad muestra diferentes grados de sensibilidad del consumidor frente al consumo del producto; es decir, cómo cambian las cantidades consumidas (compradas) frente a cambios en el precio: cuando es menor a uno, significa que los consumidores son muy poco o nada sensibles a variaciones en los precios. Si es mayor a uno, significa que los consumidores son muy sensibles a variaciones en los precios, y cuando es igual a uno, significa que los consumidores presentan una sensibilidad intermedia (ni muy alta ni muy baja) a variaciones en los precios.

La sensibilidad de los consumidores frente al precio depende básicamente de la existencia o inexistencia de otros bienes que son parecidos o son sustitutos de aquel que el consumidor está comprando. Por tanto, si existen muchos sustitutos la sensibilidad será alta y si no existen sustitutos, o son escasos, la sensibilidad será baja.

\subsection{Aproximaciones desde el Marketing}

Desde el punto de vista del mercadeo, el consumidor es mucho más que preferencias y restricciones presupuestarias. Si bien es cierto, se reconoce los aportes de la economía frente a su comportamiento, también se entiende que la sociología, la psicología, la cultura e inclusive los factores personales, hacen aportes importantes a la hora de entender las decisiones de estos sujetos en materia de consumo. En este orden de ideas se abandonan algunos supuestos del demandante típico neoclásico ya que, siguiendo a Talaya (2008:114), "El comportamiento del consumidor se puede definir como el comportamiento humano que mediante un proceso racional o irracional selecciona, compra, usa y dispone de productos, ideas o servicios para satisfacer necesidades y servicios".

Desde el lado de la economía, o más exactamente desde la neuroeconomía, otros autores como Glimcher y Fehr (2013), también han criticado el modelo neoclásico de demanda por ser excesivamente general ya que el cerebro de las personas puede trabajar de forma diferente a la hora de demandar cuando se compara con la racionalidad del homo economicus, pues según los autores el proceso de demanda se divide en una etapa de valoración y otra de decisión, donde se hace difícil mantener los supuestos comúnmente aceptados. Otros autores como Deaton y Muellbauer (1980) o Jehle y Reny (2000), en sus documentos hacen exposiciones sobre modelos matemáticos de la demanda ampliada, es decir una demanda que depende de variables que desbordan la esfera de los precios y del ingreso, e inclusive de la misma economía.

Los aspectos sociales que influyen en el consumo van desde la familia, el estatus, los roles y los grupos de referencia. Del lado de los aspectos culturales es fundamental la subcultura y la clase social; dentro de los aspectos psicológicos se encuentran la motivación, la percepción, el aprendizaje, las creencias y las aptitudes, y finalmente, en el ámbito personal es importante la edad y la etapa del ciclo de vida en la que se encuentra el consumidor, la ocupación, su situación económica, personalidad y su estilo de vida. En este sentido, las empresas tienen que cubrir 
las necesidades de los consumidores, en un proceso de adaptación constante, en donde los expertos intuyen las exigencias de los clientes y elaboran estrategias para satisfacerlas. Es por esto que existen unas preguntas básicas que el marketing debe plantearse: ¿qué compra? ¿quién compra?, ¿por qué compra?, ¿cómo lo compra?, ¿cuándo compra?, ¿dónde compra?, ¿cuánto compra?, ¿cómo lo utiliza?

De acuerdo a Hoffman y Bateson (2010:286), la decisión de comprar, a diferencia de la economía neoclásica, puede provenir de estímulos tanto internos como externos. En este orden de ideas, se reconocen cinco etapas básicas: reconocimiento de la necesidad (biológicas e impuestas), búsqueda de fuentes de información (personales, comerciales, públicas o empíricas), evaluación de alternativas (por análisis o impulso), decisión de compra (por esnobismo o factores inesperados) y una quinta etapa no considerada por la economía en general, la cual tiene que ver con el comportamiento posterior a la compra, es decir por la brecha entre la expectativa y la satisfacción o insatisfacción.

Otro aspecto a resaltar es la segmentación del mercado, es decir la separación de éste en grupos que tienen características comunes o elementos homogéneos en su interior, los cuales a su vez difieren de las características de otros, en aspectos claves como los hábitos, las necesidades, o los gustos. Se hace necesaria esta diferenciación del mercado para poder satisfacer mejor sus necesidades, y para hacer un análisis más completo, etc. Los tipos de segmentación son demográficos, geográficos, socioeconómicos, por personalidad, por beneficios buscados y por estilos de vida

Finalmente, cabe anotar que otros autores consideran que el estudio del comportamiento del consumidor dentro del marketing ha sido analizado desde hace muchos años, pero su metodología ha cambiado recientemente para volverse más científica. Por ejemplo, Usín (2014:63) considera que las orientaciones que ha tomado el análisis se basan en la economía y se rige bajo el concepto del "homo economicus", quien es un ser totalmente racional que busca maximizar su satisfacción.

En este sentido parece que el debate está abierto en el mercadeo; aquellos que apoyan la idea de alejarse de la economía ortodoxa y otros que aun ven en sus cimientos teóricos la base para explicar el comportamiento de los consumidores y la demanda.

\subsection{Estudios Aplicados}

En el caso de estudios aplicados para hábitos de consumo se destaca, para el año 2006, el realizado por el Ministerio de Agricultura, Alimentación y Medio Ambiente de España denominado "Hábitos de Consumo de Alimentos en España", exponiendo las principales características de dónde, cómo y por qué compran los residentes frutas, hortalizas y carnes frescas, al igual que si consumen, o no, alimentos ecológicos. Entre los principales hallazgos cabe destacar que la mayor parte de la compras las realizan en efectivo y sólo unos pocos pagan con tarjeta de crédito, siendo estos más del $20 \%$ de la población. A la hora de elegir el lugar en el que van a realizar la compra de los alimentos los españoles tienen en cuenta principalmente la comodidad y la calidad de los productos más que los precios y las ofertas. Para que los establecimientos sean elegidos por los consumidores deben 
brindar un buen servicio, es decir, a una mayor rapidez en las cajas, más ofertas y mejores precios, antes que la variedad de los productos y la atención al cliente.

En México, Sierra y Serrano (2002) realizaron otro estudio denominado "Patrones y hábitos de consumo en Baja California". El objetivo principal de esta investigación es identificar el patrón de consumo de la población, cuáles son sus preferencias de compra en el comercio para saber si el mercado local es competitivo o no para la población a la cual pretende satisfacer y de este modo ayudar al crecimiento económico de la población y la generación de nuevos empleos. Adicionalmente, intenta indagar por la influencia que existe del comercio fronterizo con Estados Unidos en la demanda interna.

Los resultados principales son los siguientes: dada la ubicación fronteriza de esta población es mucho más fácil acceder a productos del país vecino, por lo que es fundamental contar con la visa y con un vehículo que permita desplazarse de un lugar a otro. De la población encuestada sobresale que al menos un integrante de los hogares cuenta con la visa, lo que significa que estos hogares van a tener un mayor consumo en aquel país y que sus ingresos son provenientes del uso de dos monedas. Estos habitantes viajan con frecuencia al país vecino, lo hacen en promedio cada semana y no les interesa que tengan que esperar en la frontera dos horas ya que afirman que en los Estados Unidos van a encontrar productos de calidad y bajos precios, y que las tiendas de la frontera tienen una característica especial y es que cuando existe algún problema con el producto comprado, o el cliente no está satisfecho con el servicio prestado, se le devuelve el dinero o se le cambia el producto de forma inmediata.

A nivel nacional, Bibiana Mira (2012:2) escribió un artículo acerca de los hábitos de consumo en Colombia haciendo énfasis en las mujeres, en donde asegura que los hábitos de compra en los colombianos no se mantienen estables todo el año, sino que varían dependiendo del mes, por ejemplo, en los primeros meses el consumo de los colombianos es por necesidad ya que en diciembre han incurrido en muchos gastos navideños y de vacaciones, luego hacia mayo cuando llega el día de la madre, seguido del día del padre y el día del amor y la amistad el consumo de los colombianos ya es por gusto. De otro lado, las costumbres de consumo en los colombianos varían según la región en que cada colombiano se encuentre, pero también hay costumbres comunes. Existen varios rasgos peculiares de los colombianos, como es el hecho de preferir los colores amarillo y azul, comer carne, arroz, tamal, coca cola, hamburguesa, cerveza, no les gustan mucho las verduras, y en general, las comidas tradicionales de cada región son modificaciones de los guisos típicos de la comida española, desde el sancocho hasta el ajiaco santafereño.

Al hablar de moda, se puede decir que el 68\% de compras de este tipo se realizan en el segundo semestre del año, y en Colombia las personas se visten cada vez más casual dejando a un lado la formalidad. En el entretenimiento se encuentran las fiestas que hay en el transcurso de todo el año en diferentes regiones del país, y la otra predilección de los colombianos son las novelas, el fútbol y el internet. Otro aspecto importante es el cine, el cual es utilizado como un momento de integración ya que los colombianos no asisten solos al teatro. Y en cuanto a los libros, en Colombia cada vez se lee menos. 
Frente a la marca, en una calificación de uno a diez en cuanto a su importancia, para los productos es de ocho y para los servicios es de siete. La calidad de los productos es tan importante, que familias de bajos recursos muchas veces prefieren pagar un precio mayor por un producto de mejor calidad en alimentos y vestuario. Y en cuanto al precio hay una marcada relatividad, porque hay personas que buscan los menores precios en todos los productos, como hay otras que prefieren mayor calidad y asumen de igual forma un alto precio en los productos que consumen.

Siguiendo al DANE (2013) y su encuesta sobre la canasta familiar colombiana, los gastos de las familias han cambiado significativamente en la última década, destinando una buena parte de éstos a productos que antes no tenían tanta importancia, como las llamadas de larga distancia, los celulares, la administración de los conjuntos residenciales, comer en restaurantes, el seguro del carro, etc.

Las emociones (consumo emocional) tienen una gran influencia en el consumo de los colombianos y esto se ve reflejado con el aumento de la demanda en la segunda mitad de año. Otro factor importante y de gran influencia es la publicidad y los medios de comunicación, que guían las compras de los colombianos. Finalmente, las relaciones comerciales también se ven afectadas por la forma de ser de los colombianos, que son cálidos pero a la vez desconfiados por todos los fenómenos de violencia y engaños vividos dentro del país. Esta es la razón de que siempre se quiera pedir rebaja, porque sienten que son engañados y quieren ser los ganadores. Las principales tendencias del consumidor en el país son: la compra directa y la venta por catálogo, tienen cada vez más mercado. Los consumidores son cada vez más activos y reconocen la importancia de las cosas bien hechas, como las marcas que cuidan el medio ambiente y las de responsabilidad social. Las familias son cada vez más pequeñas y lo "light" tiene cada vez más peso en las compras.

\section{Análisis de la Información}

\subsection{Análisis Estadístico}

Para capturar los hábitos de no compra en lo corrido del año 2013 en el municipio de Popayán, se implementó una encuesta anónima en el mes de septiembre. Esta fue dirigida a personas residentes en Popayán que exclusivamente compran por fuera de la ciudad, ya sea de manera ocasional o frecuente, a través de un muestreo incidental o informal, donde al interior de este grupo los individuos se eligen de manera casual sin ningún juicio previo. Cabe anotar, siguiendo a Cuesta y Herrero (2010, p. 6) que este tipo de muestreo se clasifica como no probabilístico, ya que no se tiene certeza de que la muestra extraída sea representativa, es decir que no todos los individuos de Popayán que compran por fuera de la ciudad tienen la misma probabilidad de ser elegidos. Por tal razón todas las inferencias que se hagan solo tienen validez estadística al interior del grupo de personas encuestadas.

Los sitios de levantamiento de la información fueron principalmente centros comerciales, galerías, universidades, terminal de transportes, y barrios de todos los estratos. Como inicialmente se desconoce el tamaño de las familias que compran por fuera, se aplicó la fórmula tradicional y se obtuvo una muestra de 384 encuestas, aplicando un coeficiente de confianza del 95\%, un error del 5\%, y la máxima variabilidad (50\%) por no existir antecedentes sobre este tipo de investigaciones 
en la ciudad ${ }^{4}$. La encuesta básicamente consta de dos partes, una primera, que consulta por variables de tipo social y económicas tales como el género, estrato, niveles de educación alcanzados, e ingresos por rangos. En segundo lugar, se investiga por la frecuencia de compra, cuales son los bienes y servicios que adquieren y finalmente por los motivos que los llevan a hacerlo. A continuación se describen los principales hallazgos.

\subsection{Análisis Descriptivo}

\section{> Perfil del Encuestado}

Al aplicar la encuesta en la ciudad de Popayán, se encontró que 55.21\% de la población total encuestada son mujeres y el restante $44,79 \%$ son hombres. La edad promedio de las mujeres es de 35 años, mientras que para los hombres es de 37 años. De acuerdo a los niveles de educación, la mitad de la población cuenta con educación universitaria (50.4\%), seguido del $25.2 \%$ que cuenta con posgrado y el $15.6 \%$ que cuenta con educación secundaria. También cabe resaltar que no se encontró ninguna persona que no tuviera algún nivel de educación.

Haciendo una comparación con la Gran Encuesta Integrada de Hogares (GEIH) para el municipio de Popayán en el periodo analizado, el número de mujeres alcanza el $52.6 \%$ y los hombres el $47.4 \%$, la edad promedio de las mujeres oscila en los 38.5 años y los hombres en $36.7 \%$. Frente a los niveles de educación, la diferencia es notoria comparada con los encuestados, ya que tan solo el $18 \%$ de la población cuenta con pregrado, y el $6.2 \%$ con posgrado y el 18.3\% con educación secundaria. Finalmente, las personas que manifestaron no tener ningún tipo de educación alcanza el 5.6\%.

Frente a los niveles de ingreso, la población encuestada manifiesta que éstos se ubican entre 1 y 2 SMMLV (salarios mínimos mensuales legales vigentes de 2013), que en promedio suman $\$ 884,250$ y tiene un porcentaje del $26.8 \%$. De otro lado, el 18\% de la población cuenta con un ingreso de 3 a 4 SMMLV, que en promedio equivale $\$ 1,473,750$. Finalmente, el $6.5 \%$ de la población encuestada afirmó tener un ingreso promedio menor a un salario mínimo, es decir un ingreso de $\$ 294,750$. En la GEIH se encuentra que la población payanesa el 76.01\% de la población obtienen entre 1 y 2 SMMLV, de otro lado el $15.91 \%$ de la población cuenta con un ingreso de 3 a 4 SMMLV. Finalmente, el 7.5\% de la población encuestada afirmó tener un ingreso promedio mayor a un salario mínimo.

La población encuestada se encuentra principalmente ubicada en el estrato 3 , siendo este el $42.7 \%$, seguido del estrato 4 que representa el $22.1 \%$ y el estrato 5 que es $15.9 \%$. Estos resultados demuestran que la clase media baja es la más representativa al interior de la muestra y los estratos tanto más altos como más bajos cuentan con menor porcentaje de población. Del lado de la frecuencia de compra, es decir el grado de regularidad con que las personas compran por fuera del comercio payanés, se encuentra que el 61\% lo hacen de manera eventual y el $39 \%$ afirmó que lo hace de manera frecuente. 4. La fórmula utilizada fue $n=\frac{Z^{2} p q}{E^{2}} ; Z$ es el nivel de confianza, $p$ es la variabilidad positiva, $q$ es la
variabilidad negativa, $E$ es la precisión o error. 
En este mismo sentido, la GEIH encuentra que para la ciudad, el estrato predominante es el 2, con una participación de 46.8\%, seguido del estrato 1, con 32.3\%; el estrato 3 y 4 , abarcan el $15.4 \%$ y el restante $5.5 \%$ a los estratos 5 y 6 .

Con todo lo anterior, se puede decir que los resultados de la encuesta muestran algún grado de similitud con los resultados de la GEIH para Popayán, sobre todo en la información relacionada con género y los niveles de ingreso, aunque dista de manera moderada con los hallazgos de la clasificación de la población por estrato.

\section{Tipo de Bien}

Cuando se trata de realizar las compras por fuera de la ciudad, el bien predilecto a consumir es el vestido (30.5\%), seguido por la tecnología (17.7\%) y los alimentos (13.8) y los menos consumidos por fuera de Popayán son vivienda (2.0\%), explicado por los altos precios de la construcción; salud de nivel 2 y $3(4.0 \%)$, ya que es un bien suntuario y la educación (4.8\%), debido a que existe una alta oferta a nivel local de centros educativos del orden público y privado. Otros bienes adquiridos en menor proporción (4.8\%) son por ejemplo implementos de aseo, medicamentos, implementos deportivos, recreación, juguetería, automóviles, repuestos, maquillaje, entre otros.

Gráfico 1. Tipo de Bienes o Servicios Consumidos Fuera de Popayán. 2013

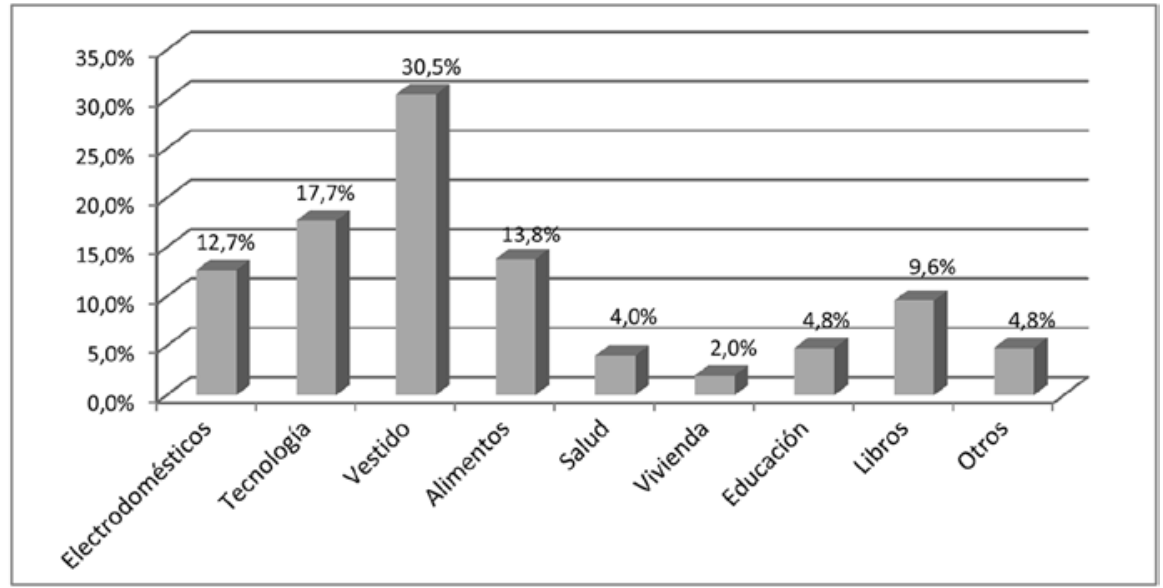

\section{> Bienes o Servicios consumidos fuera de Popayán por Género}

De acuerdo al género de los encuestados, tanto hombres como mujeres consumen principalmente vestuario por fuera de la ciudad, aunque el porcentaje es mayor en las mujeres (32.2\%), que en los hombres (28.4\%). Cabe resaltar que los hombres le dan mayor importancia al consumo de tecnología (21.2\%), mientras que las mujeres se preocupan más por consumir bienes y servicios del hogar. Los bienes menos consumidos por fuera de la ciudad tanto para hombres como para mujeres siguen siendo vivienda, salud y la educación. 


\section{Gráfico 2. Bienes o Servicios consumidos fuera de Popayán por Género.}

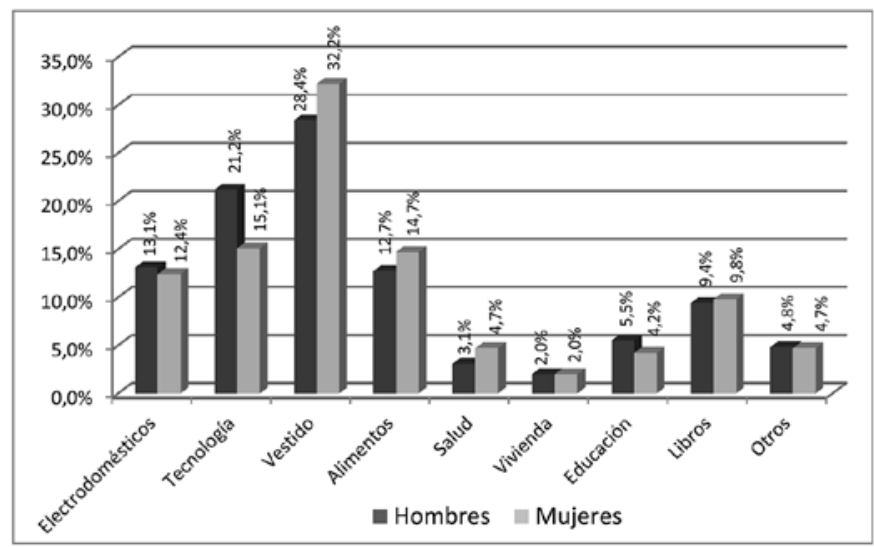

Fuente: Elaboración propia.

\section{- Motivos de No Compra}

Los principales motivos que señalaron los encuestados por los cuales no consumen bienes y servicios en el comercio de Popayán son la escasa variedad (27.1\%), los altos precios (26.2\%), por ir de paseo o recreación (15.3\%), baja calidad (13.6\%) y la mala atención al público (10.9\%). Concordando esto con la inconformidad que señalaron muchos de los encuestados de que en la ciudad generalmente no se encuentran los bienes y servicios que ellos necesitan, y por esto tienen que salir de la ciudad para poder conseguirlos. Otros motivos estipulados fueron la inexistencia o dificultades a la hora de hacer efectivas las garantías (sobre todo en los servicios), sitios de trabajo por fuera de la ciudad, familias en otra ciudad, hasta problemas de parqueo, entre otros.

Gráfico 3. Motivos de No Compra. Popayán. 2013

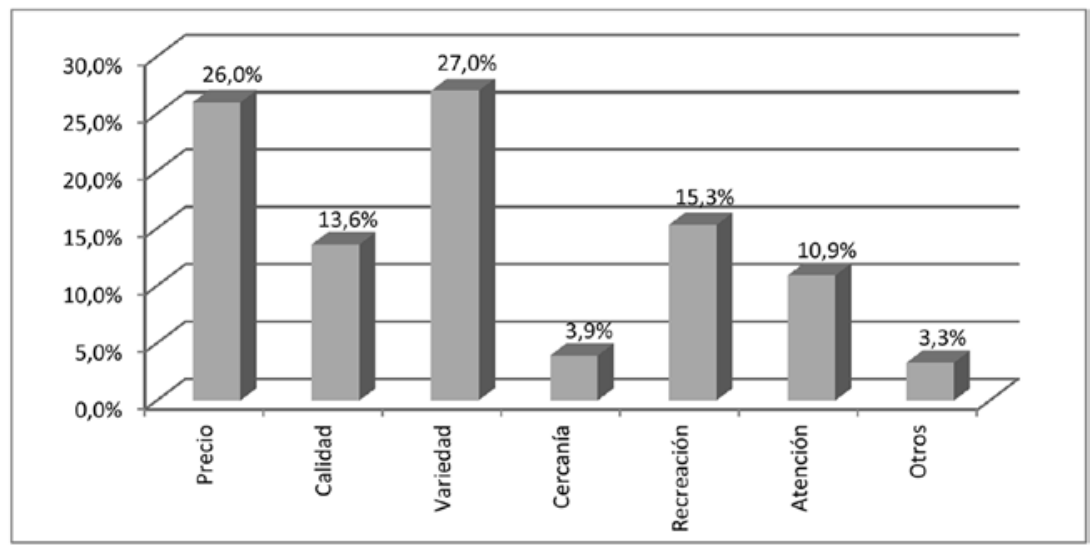

Fuente: Elaboración propia 
Cabe aclarar que no se hizo una distinción de los motivos de no compra por género de la población encuestada, debido a que no existe una diferencia significativa entre las razones de no compra que dan los hombres y las mujeres.

Frente a la frecuencia de compra por estrato a medida que aumenta el estrato las personas realizan sus compras por fuera de Popayán con mayor frecuencia, y viceversa, es decir, las compras menos frecuentes la realizan los estratos más bajos. En efecto, los estratos 2 y 3 compran el $32 \%$ de las veces por fuera, los estratos 4 y 5 alrededor de la mitad de las veces y el estrato 6 realiza todas las compras de manera frecuente. Este comportamiento obedece a factores netamente económicos ya que las familias de mayores estratos cuentan con mayores ingresos y con la posibilidad de viajar a otros lugares. Mientras que los estratos más bajos prefieren comprar en la ciudad porque al incurrir en costos de transporte, los costos totales aumentarían, y por ello realizan las compras por fuera de la ciudad con eventualidad.

De acuerdo al género las compras que se realizan por fuera de la ciudad, tanto eventual como frecuente, no tienen una diferencia significativa como se puede observar en el gráfico. El 44.68\% de las compras eventuales lo realizan los hombres y el 55.32\% lo realizan las mujeres. En cuanto a las compras frecuentes, el $44.97 \%$ son realizadas por los hombres y el $55.03 \%$ por las mujeres. Tanto las compras frecuentes como las compras eventuales son realizadas principalmente por personas con nivel de educación universitario, en el caso de las eventuales representa el $50.9 \%$ y en el caso de las frecuentes representa el $49.7 \%$, seguido por las que cuentan con posgrado. Esto tiene sentido, ya que se supone que son estas personas las que cuentan con ingresos más elevados y por tanto pueden tener acceso a una mayor cantidad de bienes y servicios tanto en la ciudad como por fuera de ella.

\section{> Perfil del Consumidor que No demanda en Popayán}

De acuerdo a los hallazgos anteriores se puede afirmar que el perfil de la población encuestada que demanda por fuera de la ciudad, es el de una mujer de 35 años que cuenta con un título universitario cuyo salario está alrededor de 3 SMMLV al mes y pertenece al estrato 3. Como es de esperarse a medida que aumentan los ingresos y el estrato de los encuestados el consumo se diversifica, pasando de ser solo vestido y alimentos a consumir además de los ya mencionados, tecnología, electrodomésticos, vivienda, etc. También con el aumento de los ingresos y el estrato cambian las razones de consumo por fuera de la ciudad, ya que para los estratos más bajos son muy importantes los precios y para los estratos altos lo que prima es la variedad y la calidad. Con respecto a la frecuencia con que se realizan las compras, se observa que existe una relación directa entre la frecuencia de compra y el estrato, a mayor estrato las compras se realizarán frecuentemente; y a menor estrato las compras se realizarán eventualmente.

\section{Sinopsis del Sector Comercial de Popayán y Cali}

La información del sector comercial de Popayán es muy limitada, y la información disponible proviene de algunas cifras publicadas por la Cámara de Comercio del Cauca con algún grado de rezago y la mayoría a nivel departamental. Una si- 
tuación contraría se experimenta con el mismo sector pero para la ciudad de Cali, donde se realizan publicaciones periódicas de la dinámica a corto y largo plazo.

A pesar de esto se puede decir en primera instancia que de acuerdo con la Cámara de Comercio del Cauca (2013), el sector comercial mostró una etapa fuerte de recesión entre los años los años 2008 a 2009, fenómeno generado básicamente por la crisis financiera mundial y por la aparición de las denominadas "pirámides” en el ámbito local, que afectaron la demanda interna por la restricción en el consumos de los hogares con el fin de destinar sus recursos a las captadoras ilegales de dinero. Ya para 2013, la situación ha cambiado y se encuentra que su valor agregado experimentó un alza del 4.8\%, superando el comportamiento nacional. Básicamente el comercio de vehículos y las crecientes expectativas de retornos por inversiones en hotelería son los responsables de dicho comportamiento. Según esta entidad, la actividad comercial es vista en Popayán y el Cauca, en muchos casos como una opción de consecución de ingresos debido a los altos niveles de desempleo de la ciudad, los cuales, alcanzan el 18\% en promedio para los últimos años.

Una consecuencia de lo anterior es la alta presencia de informalidad en el sector comercial de la ciudad, factor que ha dificultado hacerle un seguimiento periódico a la actividad. De acuerdo con la Cámara de Comercio del Cauca (2011; 2014), el número de establecimientos formales allí registrados asciende a 3,733 e informales 1,784, es decir estos últimos representan alrededor del $32 \%$. Otras cifras encuentran que las microempresas informales se dedican principalmente a actividades de tipo comercial (53.3\%), servicios comunales y personales (18.4\%) y restaurantes y hoteles (11\%), debido a los bajos niveles de inversión requeridos para su constitución. El 66.38\% no llevan ningún tipo de registro contable, lo que dificulta el cálculo real de sus ingresos y utilidades mensuales. Finalmente, al menos el 90\% de las microempresas informales generan entre 1 y 2 empleos directos, sin embargo un gran porcentaje no realiza el pago de aportes de seguridad social lo que deviene en empleos de baja calidad.

En el caso de la ciudad de Cali, de acuerdo a la Cámara de Comercio de Cali (2014), el sector comercio representa 40,6\% de las empresas registradas $(28,985)$, de las cuales el $92.4 \%$ son microempresas, el $6.0 \%$ pequeñas, $1.4 \%$ medianas y $0.3 \%$ grandes. Las empresas dedicadas al comercio al por menor representan $76.7 \%$ del sector, de los cuales un $12.2 \%$ se dedican a la venta de alimentos y bebidas en almacenes, misceláneas y cacharrerías, otro 10\% a la venta de prendas de vestir y accesorios y un restante $8 \%$ a la venta de artículos de ferretería y vidrio.

Las empresas más representativas dentro del grupo de comercio mayorista (16.4\%) se dedican a la venta de maquinaria y equipos de oficina, transporte, eléctrico, entre otros. La venta al por mayor de productos alimenticios (10.8\%) ocupa un segundo lugar, seguido de las empresas que venden materiales de construcción, artículos de ferretería, fontanería, calefacción, entre otros. Finalmente, el comercio, mantenimiento y reparación de vehículos abarca el 9.6\% de las empresas pertenecientes al sector comercio. Del lado de la informalidad 21,929 establecimientos no están registrados ante la Subdirección de Rentas e Impuestos Municipales, los cuales se conforman entre graneros, estaciones de gasolina, supermercados, distribuidoras, discotecas, almacenes de ropa y panaderías. 
Hacer una comparación entre los dos sectores resulta difícil ya que como se señaló con anterioridad la información para el sector comercial de Popayán es escasa por no decir nula. Sin embargo, con lo que muestran las cifras anteriores se puede decir que el número de empresas registradas en Cali supera al de Popayán en una relación de 9 a 1, lo que evidencia el tamaño del sector en términos comparativos, pero la informalidad se comporta de manera inversa, es decir el hay mas empresa informales en Cali que en Popayán en dicho sector (40\% frente a 32\%). El tamaño del sector podría convertirse en una razón de fugas de demanda desde Popayán hacia Cali, pues un mayor tamaño puede significar una mayor cantidad, variedad y calidad de los productos.

\section{Resultados Principales de los Modelos}

Para analizar de manera más profunda por qué las familias residentes en Popayán compran por fuera de la ciudad, se construyeron tres modelos econométricos que pertenecen al segmento de los modelos de variable dependiente limitada (Modelos Logit). La pretensión con ellos no es otra que mostrar las probabilidades de compra por frecuencia, tipo y motivos, teniendo en cuenta las variables socioeconómicas relacionadas con anterioridad.

\subsection{Modelo Logit}

El modelo utilizado en el estudio es Logit o logístico, el cual hace parte del grupo de los llamados modelos de elección discreta. Vale la pena mencionar que las aplicaciones empíricas aquí realizadas provienen todas de dicho enfoque. Dentro de los modelos de elección discreta más utilizados, a parte del logístico se encuentran los Modelos de Probabilidad Lineal (MPL), y los modelos Normit o Probit.

No se utilizan aquí estos dos últimos debido a que los modelos MPL por ejemplo siempre presentan diferentes problemas como el que los errores aleatorios no sigan una distribución normal, sin contar con la presencia de heterocedasticidad, bajas medidas de bondad de ajuste, probabilidades que no cumplen con el supuesto de ubicarse entre cero y uno, y finalmente que los cambios en la probabilidad de éxito siempre son inmodificables. Del lado de los modelos Probit tampoco, ya que se basan en que la variable endógena sigue una distribución normal, pero dado que el muestreo aplicado en el estudio es incidental, es poco probable que se cumpla dicho requerimiento. Adicionalmente, la inclusión de variables dicotómicas como variables explicativas contribuye a que no se cumplan con el supuesto de normalidad.

Por todas las anteriores razones se utiliza un modelo Logit, el cual se caracteriza porque la elección presenta solo dos alternativas posibles mutuamente excluyentes (éxito o fracaso), y por tanto la variable endógena del modelo es binaria. El modelo Logit se basa en una función de distribución logística para los errores aleatorios, y su estimación se hace a través del método de Máxima Verosimilitud (MV). Además, el modelo Logit se caracteriza porque la probabilidad se ubica entre 0 y 1 , el coeficiente de determinación es alto, y la modificación de la probabilidad ante cambios en una variable exógena, siempre es variable. 
Cuando se utiliza la función de distribución logística acumulativa, la probabilidad de éxito se expresa así:

$$
P_{i}=\frac{1}{1+e^{-Z_{i}}}=\frac{e^{Z_{i}}}{1+e^{Z_{i}}}
$$

Y la de fracaso es:

$$
1-P_{i}=\frac{1}{1+e^{Z_{i}}}
$$

Dónde: $\quad Z_{i}=\beta_{1}+\beta_{2} X_{2 i}+\cdots+\beta_{k} X_{k i}$

La división de probabilidades de éxito y fracaso se conoce como la razón de probabilidad a favor que el evento suceda o también como odds ratios:

$$
\frac{P_{i}}{1-P_{i}}=\frac{\frac{e^{Z_{i}}}{1+e^{Z_{i}}}}{\frac{1}{1+e^{Z_{i}}}}=\frac{e^{Z_{i}}\left(1+e^{Z_{i}}\right)}{1+e^{Z_{i}}}=e^{Z_{i}}
$$

$\mathrm{Al}$ introducir logaritmos a ambos lados naturales se tiene que:

$$
\operatorname{Ln}\left[\frac{P_{i}}{1-P_{i}}\right]=L_{i}=\beta_{1}+\beta_{2} X_{i}
$$

Debe resaltarse que cuando Li tiende a menos infinito, la probabilidad de éxito tiende a cero y cuando tiende a la unidad, la probabilidad tiende a uno. De otro lado, la modificación de la probabilidad que suceda el evento cuando se modifica no es constante, sino variable y cambia de acuerdo a la probabilidad de éxito y de fracaso para cada $\mathrm{i}$.

$$
\begin{gathered}
\frac{d P_{i}}{d X_{i}}=\frac{\beta_{2} e^{z}\left(1+e^{z}\right)-\beta_{2} e^{z}\left(e^{z}\right)}{\left(1+e^{z}\right)^{2}}=\beta_{2} \frac{e^{z}}{\left(1+e^{z}\right)} \frac{1}{\left(1+e^{z}\right)} \\
=\beta_{2}\left[P_{i}\left(1-P_{i}\right)\right]
\end{gathered}
$$


Finalmente, se debe decir que en el modelo logit los errores son heterocedásticos, pues se distribuyen de la siguiente forma:

$$
U_{i} \sim N\left(0, \frac{1}{N P_{i}\left(1-P_{i}\right)}\right)
$$

Dicho inconveniente se puede resolver obteniendo covarianzas robustas a través de la sugerencia de Huber-White o bajo la estimación del modelo por el método del Modelo Lineal Generalizado (GML).

\subsubsection{Modelo Logit de Compra por Frecuencia}

De acuerdo a lo establecido anteriormente, los modelos son los siguientes:

$$
\begin{aligned}
& \operatorname{Compra}_{i}=\beta_{1}+\beta_{2} \text { Gen }_{i}+\beta_{3} \text { Edad }_{i}+\beta_{4} \text { Aedu }_{i}+\beta_{5} \text { Est }_{i}+\beta_{6} \text { Ing }_{i}+U_{i} \\
& \mathrm{i}=1, \ldots, 384 .
\end{aligned}
$$

Donde Compra es una variable dicotómica que asume el valor de 1 si la compra por fuera de Popayán es frecuente y 0 si es eventual. Como se observa, estas variables están explicadas siempre por variables sociales y económicas. En este orden de ideas, Gen, es el género el cual asume el valor de cero si es mujer y 1 si es hombre. Edad, corresponde a la edad del individuo, mientras que Aedu son los años de educación, Est hace referencia al estrato donde vive la persona, e Ing muestra el ingreso devengado por mes. Finalmente, $\mathrm{U}_{\mathrm{i}}$ es una variable aleatoria que se supone ruido blanco.

El modelo muestra una significancia buena de manera conjunta e individual, ya que el p-valor de todas las variables consideradas es inferior al $10 \%$, y el p valor de Wald es cercano al $0 \%$. De otro lado se analizó la matriz de correlaciones para indagar por problemas de multicolinealidad (no mostrada aquí), pero no existen fuertes indicios de su presencia ${ }^{5}$.

En una primera aproximación la estimación mostró que para el grupo encuestado, sin importar si es hombre o mujer, el consumidor demanda frecuentemente $o$ eventualmente siempre en la misma proporción. De otro lado, a medida que la edad aumenta, caen la probabilidad de hacer compras frecuentes por fuera de la ciudad, es decir que son las personas más jóvenes quienes más demandan por fuera. Algo similar ocurre con los niveles de formación educativa, ya que entre más años tenga la persona, es menos proclive a comprar frecuentemente por fuera. Este resultado

5. Los resultados se muestran en el anexo 1. 
va de la mano con el anterior, ya que las personas de edad más avanzada son las que posiblemente tengan más años de estudio acumulados. Frente al estrato y al ingreso la situación es inversa. Si el estrato y el ingreso son más altos, la probabilidad de que aumente el consumo externo, cada vez es mayor.

Si se toman los valores promedios arrojados por la encuesta para la edad, los años de educación, el estrato y el ingreso, la probabilidad de compra en el comercio de otra ciudad diferente a Popayán, es del 38.18\% para el grupo de referencia. Esto traduce que si una persona de la población encuestada tiene 36 años, 15 años de educación, pertenece al estrato 3 , y tiene un ingreso cercano a 2 millones de pesos, la probabilidad de que compre de manera prolífica por fuera es cercana al 38\% y de que lo haga de forma poco frecuente es del 42\%. Para ahondar en los resultados obtenidos del grupo, se estimó el modelo discriminando por todos los estratos, lo cual requiere que las variables explicativas sean tomadas en promedio para cada una de las estratificaciones sociales. La tabla siguiente muestra los resultados de manera sintética ${ }^{\mathbf{6}}$ :

Tabla 1. Probabilidad de Compra Frecuente por Estrato

\begin{tabular}{|l|r|r|r|r|r|r|}
\hline \multicolumn{1}{|c|}{ Variable } & Estrato 1 & Estrato 2 & Estrato 3 & Estrato 4 & Estrato 5 & Estrato 6 \\
\hline Edad & 29,7 & 32,6 & 34,4 & 40,2 & 39,7 & 47,0 \\
\hline Aedu & 12,1 & 13,7 & 15,5 & 16,6 & 17,5 & 19,2 \\
\hline Est & 1 & 2 & 3 & 4 & 5 & 6 \\
\hline Ing & $\$ 736.875$ & $\$ 1.209 .077$ & $\$ 1.775 .689$ & $\$ 2.479 .368$ & $\$ 2.778 .381$ & $\$ 3.360 .150$ \\
\hline Probabilidad & $20,65 \%$ & $26,95 \%$ & $34,67 \%$ & $44,24 \%$ & $54,79 \%$ & $61,88 \%$ \\
\hline
\end{tabular}

Fuente: Elaboración propia

La tabla muestra que la posibilidad de compras frecuentes se eleva en la medida que el nivel de estrato aumenta, o lo que es lo mismo, la posibilidad de compras eventuales guarda una relación inversa con el estrato en el grupo de referencia. En efecto, para el estrato 1 la probabilidad de compra por fuera es del $20.65 \%$, para el estrato 2 asciende alrededor de $27 \%$, ya para el estrato 3 es aproximadamente igual al 35\%; en el estrato 4 es del 44,24\%; en el estrato 5 es del 54.7\% y finalmente en el estrato 6 es casi del 62\% ${ }^{7}$. La explicación a este fenómeno obedece a que las personas de mayor estratificación presentan mayores niveles de estudio y por tanto mayores niveles de ingreso, lo que les permite tener un mayor acceso a consumos foráneos. Adicionalmente el costo de realizar dichas compras es más bajo ya que dichas familias poseen automóviles, tarjetas de crédito, tarjetas débito, acceso a internet, entre otros.

6. Los resultados completos se muestran en el anexo 2.

7. Las probabilidades de fracaso, es decir que compren por fuera de manera eventual, es igual a lo que le resta a cada probabilidad para ser igual al 100\%. Por ejemplo, en el estrato 1 la posibilidad de compra infrecuente es igual al 79,35\%. 


\subsubsection{Modelo Logit de Compra por Tipo de Bien ${ }^{8}$}

Para capturar las probabilidades de compra discriminadas por el tipo de bienes comprados por fuera de la ciudad de acuerdo a un conjunto de atributos sociales y económicos de la población encuestada, se implementó también un modelo logístico. La variable Tipo asume el valor de 1 si compra un bien o servicio en particular y asume el valor de 0 para otro caso.

$$
\begin{gathered}
\text { Tipo }_{i}=\beta_{1}+\beta_{2} \text { Gen }_{i}+\beta_{3} \text { Edad }_{i}+\beta_{4} \text { Aedu }_{i}+\beta_{5} \text { Est }_{i}+\beta_{6} \text { Ing }_{i} \\
+\varepsilon_{i} \quad \text { (8) }
\end{gathered}
$$

Las restantes variables se definen como en el modelo 1. Finalmente $\varepsilon_{\mathrm{i}}$ es una variable aleatoria bien comportada ruido blanco. Algunos modelos muestran variables con significancias estadísticas muy bajas, por lo tanto han sido elegidas como variables de control. Las pruebas de asociación global evidencian buenos ajustes,

\begin{tabular}{|c|c|c|c|c|c|c|c|c|}
\hline Variable & $\begin{array}{l}\text { Electrodo- } \\
\text { mésticos }\end{array}$ & Vestuario & Alimento & Salud & Vivienda & Educación & Libros & Otros \\
\hline Edad & & & & 36,2 & & 36,2 & & \\
\hline Gen & & 0 & & 0 & & & & \\
\hline Aedu & 15,74 & & & & & & 15,74 & 15,74 \\
\hline Est & 3 & 3 & 3 & & & & 3 & \\
\hline Ing & $\$ 1.984 .957$ & & & $\$ 1.984 .957$ & $\$ 1.984 .957$ & \$1.984.957 & \$1.984.957 & \\
\hline Probabilidad & $32,41 \%$ & $89,07 \%$ & $35,22 \%$ & $12,07 \%$ & $4,45 \%$ & $10,46 \%$ & $21,42 \%$ & $12,13 \%$ \\
\hline
\end{tabular}
como el p-valor del test de Wald.

Tabla 2. Probabilidad de Compra Frecuente por Tipo de Bien o Servicio

Fuente: Elaboración propia

Los resultados evidencian que la mayor prevalencia de compras por fuera se realiza en vestuario (ropa y zapatos en general) con una probabilidad muy elevada frente a los otros bienes o servicios. En efecto, de cada 100 compras que hacen las personas de la población encuestada por fuera del comercio payanés en vestuario, 89 se hacen de forma frecuente y solo 11 se hacen de manera ocasional.

Los restantes consumos en otros bienes o servicios de dicha población están muy distantes de tan altas frecuencias, por ejemplo los alimentos que ocuparían

8. La explicación y los resultados completos del modelo se muestran en el anexo 3. 
el segundo lugar en importancia, no alcanzan a presentar ni la mitad de la probabilidad de compra (35.2\%) del vestuario. Un comportamiento similar muestra los electrodomésticos, ya que el $32 \%$ de las veces se compra de manera frecuente en otras ciudades. Seguidamente, los libros evidencian una frecuencia de compra del $21 \%$ aproximadamente, resultado que es acorde con una ciudad que se cataloga como universitaria. En un renglón aparte se encuentra otros bienes (implementos de aseo, medicamentos, implementos deportivos, recreación, juguetería, automóviles, repuestos, maquillaje, entre otros) con una probabilidad cercana al 12\%. Con una probabilidad similar se halla la salud de niveles 2 y 3 (12\%); y cierra el grupo la educación con una prevalencia del 10\%.

Finalmente, las compras menos frecuentes que se hacen por fuera de la ciudad de Popayán, hacen referencia a la vivienda. Este resultado es coherente toda vez que las personas primero resuelven su problema de propiedad raíz en la ciudad donde viven y luego pueden llegar a hacerlo por fuera de la ciudad. De otro lado, vale la pena mencionar que aunque no hace parte del sector comercial, la vivienda se referencia aquí debido a que su compra jalona a otros sectores de la economía, como el comercial, ya que las viviendas nuevas demandan electrodomésticos, muebles, adornos, entre otros.

\subsubsection{Modelo Logit de Compra por Motivo ${ }^{9}$}

El modelo implementado es el siguiente:

$$
\begin{aligned}
& \text { Motivo }_{i}=\beta_{1}+\beta_{2} \text { Gen }_{i}+\beta_{3} \text { Edad }_{i}+\beta_{4} \text { Aedu }_{i}+\beta_{5} \text { Est }_{i}+\beta_{6} \text { Ing }_{i} \\
& +\theta_{i} \\
& \text { (9) } \\
& i=1, \ldots, 384 .
\end{aligned}
$$

Las restantes variables se definen como en el modelo 1. $\theta_{\mathrm{i}}$ es una variable aleatoria ruido blanco. Como en el caso anterior se controló la modelación con las variables más multicolineales. A pesar de lo anterior, las pruebas de asociación global evidencian buenos ajustes, como el p-valor del test de Wald. La tabla siguiente muestra que el principal motivo por el cual las personas de la muestra demandan por fuera de la ciudad, obedece a la escasa variedad en los bienes y/o servicios ofrecidos por el comercio local. En efecto, la probabilidad de que una persona compre frecuentemente por fuera debido a esta motivación, asciende al 73.7\%. Otro motivo que presenta una alta prevalencia son los precios. Los resultados muestran que la probabilidad de compra frecuente por fuera de la ciudad es del 65\% aproximadamente.

9. La explicación y los resultados completos del modelo se muestran en el anexo 4 . 
Tabla 3. Probabilidad de Compra Frecuente por Motivo

\begin{tabular}{|l|r|r|r|r|r|r|r|}
\hline \multicolumn{1}{|c|}{ Variable } & \multicolumn{1}{c|}{ Precios } & Calidad & \multicolumn{1}{c|}{ Variedad } & Cercanía & Recreación & Mala Atención & Otros \\
\hline Edad & 36,2 & & & & & & 36,2 \\
\hline Gen & & & 0 & & & 0 & \\
\hline Aedu & & & 15,7 & 15,7 & 15,7 & 15,7 & \\
\hline Est & & & & & & 3 & \\
\hline Ing & & $\$ 1.984 .957$ & & & & & \\
\hline Probabilidad & $\mathbf{6 5 , 0 3 \%}$ & $\mathbf{3 3 , 8 1 \%}$ & $\mathbf{7 3 , 7 5 \%}$ & $\mathbf{9 , 3 5 \%}$ & $\mathbf{3 8 , 2 0 \%}$ & $\mathbf{2 9 , 1 2 \%}$ & $\mathbf{7 , 6 0 \%}$ \\
\hline
\end{tabular}

Fuente: Elaboración Propia

De manera más distante con una probabilidad casi inferior a la mitad de los anteriores motivos, se encuentra la recreación con un 38.2\%. Esto traduce que es menos probable que la población encuestada compre de manera frecuente por fuera, para aprovechar y salir de paseo con la familia. Lo que generalmente ocurre entonces, es que no es tan frecuente que ellas salgan de paseo y compren en otra ciudad. Con una probabilidad similar se encuentra el motivo calidad. Esta asciende al $33.8 \%$ para compras frecuentes y por tanto a $67.2 \%$ para compras eventuales. Aunque se puede pensar que la calidad es homogénea debido a que en Popayán hay muy poca manufactura y por tanto la mayoría de los bienes son trasladados de otras ciudades y revendidos localmente, existen otros bienes (o servicios) como los muebles y enseres que son creados aquí. Los encuestados de estratos altos manifestaron por ejemplo que por seguridad, calidad y garantía, adquieren estos bienes en otras ciudades como Cali.

El motivo mala atención al público muestra una prevalencia del 29.12\%, la cual no solo hace alusión al trato de los vendedores para con los compradores, sino también a los horarios de atención al público. En su mayoría las personas que hacen alusión a este motivo son personas de la muestra que provienen de otras ciudades y que tienen por tanto puntos de comparación con otros entornos. La cercanía revela una probabilidad cercana al 9\%. Esto evidencia que pocas compras frecuentes se realizan debido a que el sitio de demanda es cercano, geográficamente hablando, y más bien son las compras eventuales las que tienen en cuenta este factor. Otros motivos, tales como falta de garantías sobre todo en los servicios, sitios de trabajo por fuera de la ciudad, familias en otra ciudad hasta problemas de aparcamiento entre otros, reflejan muy poca frecuencia en el gasto (7.6\%) de la población del estudio.

\section{Conclusiones}

Del total de la población encuestada, son las mujeres quienes compran por fuera de la ciudad con más frecuencia que los hombres (55.03\% frente a 44.97\%). El bien que más se demanda es vestido (ropa, zapatos, accesorios) tanto por hombres como por mujeres aunque en proporciones diferentes. Le siguen otros bienes tales como la tecnología (más en hombres que en mujeres), alimentos (más en mujeres que en 
hombres) y electrodomésticos casi por igual en ambos sexos. La vivienda, la salud de tipo 2 y 3, y la educación son demandados en una menor proporción. Finalmente, otros bienes demandados son implementos de aseo, medicamentos, implementos deportivos, recreación, juguetería, automóviles, repuestos, maquillaje, entre otros.

El principal factor que manifiestan los encuestados para no comprar dentro de la ciudad bienes y servicios es la variedad, seguida por los precios bajos (aunque esto depende del estrato al que pertenezcan), por la calidad y por el motivo recreación, es decir, por ir de paseo con la familia. Otros factores considerados son la atención al público, la cercanía con la ciudad oferente, y con una proporción más baja otros motivos tales como la presencia y cumplimiento de garantías sobre todo en lo relacionado con los servicios, trabajo por fuera de Popayán, presencia de familiares en la ciudad donde demandan y hasta problemas de estacionamiento.

Los resultados de los modelos estocásticos muestran que existe una correspondencia directa con los resultados descriptivos de la población de referencia. En efecto, el estrato 1 muestra una probabilidad del $20.65 \%$ de comprar por fuera de manera frecuente, el estrato 3 alcanza una probabilidad del $34.67 \%$ y el estrato 6 del 61.9\%. Los bienes que es más probable que se compren por fuera de Popayán son: vestuario (89.07\%); alimentos $53.22 \%$ y electrodomésticos (32.41\%). Y finalmente, los motivos por los que compran son variedad (73.8\%), precios (65\%), recreación (38.2\%) y calidad (33.8\%).

La cercanía de la ciudad a Cali impide una consolidación del sector, tanto desde la oferta como desde la demanda. La dependencia es muy alta de esta ciudad a todo nivel: trabajo, comercio, transporte (terrestre y aéreo), puerto marítimo (en Buenaventura), entre otras. En otras palabras Popayán se encuentra en la periferia de un centro que es la ciudad de Cali en materia de comercio, ya que en su radio de influencia económica está Popayán, situación que no sucede con Pasto por ejemplo.

Como es fácil para los consumidores payaneses de estratos altos de la muestra acceder a bienes sustitutos ofrecidos por otras ciudades como Cali, o inclusive lejanas por medio de la tecnología, la sensibilidad o elasticidad de estos consumidores es alta. Es decir, tienen el poder adquisitivo y son sensibles a alzas en los precios. De manera diferente, aquellos que pertenecen a estratos bajos son sensibles a los precios altos, existan o no sustitutos en Cali, ya que no tienen poder adquisitivo. Esto lleva a que el sector comercial se encuentre en el peor de los escenarios, ya que la fuga de demanda se presenta por el lado de familias de estratos medios y altos, y quienes demandan al interior son familias que tienen altas sensibilidades a los precios.

Frente a las cuatro variables que según la teoría del mercadeo debe tener toda empresa para impulsar un bien o servicio (producto, precio, plaza y promoción), el comercio de la ciudad está en clara desventaja frente a su competidor inmediato que es la ciudad de Cali. De acuerdo a la opinión de los encuestados carecen de calidad, empaque y marca; frente al precio son relativamente más altos y además se consideran muy poco las formas de pago, el tiempo de financiación, los descuentos y los recargos del producto. La plaza o lugar de distribución se realiza en almacenes ubicados solo en la parte céntrica y tan solo existen actualmente tres centros comerciales: Anarkos, Plaza Colonial y Campanario, donde la promoción, 
relaciones públicas, merchandising y servicio al cliente, para posicionar las marcas o producto específicos solo se impulsan generalmente en el último.

Para auxiliar al sector comercial local se debería realizar una campaña publicitaria agresiva, la cual podría denominarse "Payanés compra a Payanés", a través de prensa, televisión, radio, internet, vallas, flayers, entre otros, que concientice a los demandantes locales que una forma de impulsar el desarrollo y crecimiento de la ciudad es que las compras se realicen aquí. La campaña debe dejar claro o persuadir que el sector es competitivo, sobre todo en precios, variedad, calidad y que los artículos traídos de Cali u otras ciudades incrementan su precio por el flete y no generan empleo en la ciudad. Esta campaña debe estar acompañada de una revista o boletín que informe a la ciudadanía sobre sitios, precios, rebajas, promociones, horarios, entre otros, para que se induzca al demandante a que compre en Popayán.

Adicionalmente, se deben prestar asesorías técnicas y acompañamientos continuos a los negocios del sector comercial payanés para poner en práctica las recomendaciones que desde el marketing se realizan y que permitan retener o ampliar la demanda, tales como aprender a definir la orientación psicológica y motivacional del consumidor, tener la capacidad de poder segmentar el mercado, conocer estrategias de venta y publicidad, entre otras.

\section{REFERENCIAS BIBLIOGRÁFICAS}

1. CÁMARA DE COMERCIO DE CALI (2014). Apunte Económico. Unidad Económica y de Planeación. Cali. 5p.

2. CÁMARA DE COMERCIO DEL CAUCA (2014). 200 Empresas Generadoras de Desarrollo en el Cauca. Popayán. 47p.

3. CÁMARA DE COMERCIO DEL CAUCA (2011). Estudio de Identificación de Potenciales Beneficiarios del Programa Formalización. 77p.

4. CUESTA, Marcelino y HERRERO, Francisco (2010). Introducción al Muestreo. Working Paper. Departamento de Psicología. Universidad de Oviedo. 9p.

5. DEATON, Angus y MUELLBAUER, Jhon (1980). Economics and Consumer Behavior. Cambridge University Press, Cambridge. 447p.

6. DANE (2013). Índice de Precios al Consumidor. Comunicado de Prensa. 4p. [En línea] Disponible en: http://www.dane.gov.co/files/investigaciones/boletines/ipc/cp_ipc_jul13.pdf

7. FERNÁNDEZ DE CASTRO, Juan y TUGORES, Juan (1998). Microeconomía. McGraw Hill. Barcelona. Primera Edición. 458p. 
8. FONDO SOCIAL EUROPEO Y SERVICIO ANDALUZ DE EMPLEO (2007). Estudio del Sector Comercial de Motril. España. 400p. [En línea] Disponible en: http://www.motril.es/index.php?id=1255

9. GLIMCHER, Paul y FEHR, Ernst (2013). Neuroeconomics: Decision Making and the Brain. Academic Press: New York. 560p.

10. HOFFMAN, Douglas; BATESON, Jhon (2010). Services Marketing: Concepts, Strategies \& Cases. SouthWestern. Mason, USA. Fourth Edition. 461p.

11. JEHLE, Geoffrey y RENY, Phillip (2000). Advanced Microeconomic Theory. 2nd Edition. Addison Wesley: Reading.672p.

12. MINISTERIO DE AGRICULTURA, ALIMENTACIÓN Y MEDIO AMBIENTE DE ESPAÑA (2006). Hábitos de Consumo de Alimentos en España. Madrid. 398p. [En línea] Disponible en http://www.magrama. gob.es

13. MIRA, Bibiana (2012). Hábitos de Consumo en Colombia. Suramericana de Seguros [En línea] Disponible en: http://www.sura.com/blogs/mujeres/habitos-consumo-colombia.aspx

14. NICHOLSON, Walter (2000). Teoría Microeconómica: Principios Básicos y Ampliaciones. Thompson. Madrid. Sexta Edición. 745p.

15. ORMET (2013). Informe de Diagnóstico del Mercado de Trabajo de Popayán. Observatorio Regional del Mercado de Trabajo. Ministerio de Trabajo, Departamento para la Prosperidad Social (DPS), Plan de Naciones Unidas para el Desarrollo (PNUD) y Universidad del Cauca. Popayán. 97p.

16. PINDYCK, Robert y RUBINFELD, Daniel (1998). Microeconomía. Prentice Hall. Madrid. Cuarta Edición. $630 \mathrm{p}$.

17. SIERRA, Olga; SERRANO, Sandra (2002). "Patrones y hábitos de consumo en Baja California”. En: Comercio Exterior. Vol. 5, Numero 8. Agosto. Ciudad de México, México, pp. 701-708.

18. TALAYA, Esteban; GARCIA, Jesús; NARROS, María; OLARTE, Cristina; REINARES, Eva, SACO, Manuela (2008). Principios de Marketing. ESIC Editorial. Madrid, España. Tercera Edición. 815p.

19. VARIAN, Hal (2000). Microeconomía Intermedia: Un Enfoque actual. Editorial Alfa Omega. Colombia. Quinta Edición. 726p.

20. USÍN, Sandra (2014). Experiencia de Compra de los Consumidores de Centros Comerciales de Vizcaya. Tesis Doctoral. 567p. Universidad Politécnica de Valencia. [En línea] Disponible en: http://hdl.handle. net/10810/12458. 


\section{ANEXOS}

Anexo 1. Estimación Modelo 1

\begin{tabular}{|c|c|l|l|l|l|r|}
\hline Logistic regression & & & & & Number of obs & 384 \\
\hline & & & & & Wald chi2(5) & 21,22 \\
\hline & & & & & Prob > chi2 & 0,0007 \\
\hline & & & & & Pseudo R2 & 0,0439 \\
\hline & & Robust & & & & \\
\hline compra_f & Coef. & Std. Err. & $z$ & P>z & {$[95 \%$ Conf. } & Interval] \\
\hline & & & & & & \\
\hline gen & $-0,0143804$ & 0,2184259 & $-0,07$ & 0,948 & $-0,4424872$ & 0,4137265 \\
\hline edad & $-0,0165237$ & 0,0099035 & $-1,67$ & 0,095 & $-0,0359342$ & 0,0028868 \\
\hline est & $-0,082248$ & 0,0399039 & $-2,06$ & 0,039 & $-0,1604582$ & $-0,0040378$ \\
\hline ing & 0,4218044 & 0,1218067 & 3,46 & 0,001 & 0,1830676 & 0,6605412 \\
\hline cons & $2,26 \mathrm{E}-07$ & $1,22 \mathrm{E}-07$ & 1,85 & 0,064 & $-1,35 \mathrm{E}-08$ & $4,65 \mathrm{E}-07$ \\
\hline & $-0,4418874$ & 0,6767906 & $-0,65$ & 0,514 & $-1,768373$ & 0,8845979 \\
\hline
\end{tabular}

Fuente: Elaboración propia 
Anexo 2. Resultados Totales Probabilidad de Compra Frecuente por Estrato

\begin{tabular}{|c|c|c|c|c|c|c|c|c|}
\hline Variable & $\mathrm{dy} / \mathrm{dx}$ & Std. Err. & $\mathbf{z}$ & $P>z$ & [ $95 \%$ & C.I. ] & $x$ & $\operatorname{Pr}$ \\
\hline edad & 0,00 & 0,00 & $-1,63$ & 0,10 & $-0,01$ & 0,00 & 29,70 & \multirow{4}{*}{0,207} \\
\hline aedu & $-0,01$ & 0,01 & $-1,89$ & 0,06 & $-0,03$ & 0,00 & 12,10 & \\
\hline est & 0,07 & 0,01 & 4,90 & 0,00 & 0,04 & 0,10 & 1,00 & \\
\hline ing & 0,00 & 0,00 & 1,76 & 0,08 & 0,00 & 0,00 & 736875 & \\
\hline edad & 0,00 & 0,00 & $-1,67$ & 0,10 & $-0,01$ & 0,00 & 32,60 & \multirow{4}{*}{0,270} \\
\hline aedu & $-0,02$ & 0,01 & $-2,00$ & 0,05 & $-0,03$ & 0,00 & 13,70 & \\
\hline est & 0,08 & 0,02 & 4,09 & 0,00 & 0,04 & 0,12 & 2,00 & \\
\hline ing & 0,00 & 0,00 & 1,83 & 0,07 & 0,00 & 0,00 & 1200000 & \\
\hline edad & 0,00 & 0,00 & $-1,67$ & 0,10 & $-0,01$ & 0,00 & 34,40 & \multirow{4}{*}{0,347} \\
\hline aedu & $-0,02$ & 0,01 & $-2,07$ & 0,04 & $-0,04$ & 0,00 & 15,60 & \\
\hline est & 0,10 & 0,03 & 3,58 & 0,00 & 0,04 & 0,15 & 3,00 & \\
\hline ing & 0,00 & 0,00 & 1,85 & 0,06 & 0,00 & 0,00 & 1800000 & \\
\hline edad & 0,00 & 0,00 & $-1,68$ & 0,09 & $-0,01$ & 0,00 & 40,20 & \multirow{4}{*}{0,442} \\
\hline aedu & $-0,02$ & 0,01 & $-2,06$ & 0,04 & $-0,04$ & 0,00 & 16,60 & \\
\hline est & 0,10 & 0,03 & 3,41 & 0,00 & 0,04 & 0,16 & 4,00 & \\
\hline ing & 0,00 & 0,00 & 1,84 & 0,07 & 0,00 & 0,00 & 2500000 & \\
\hline edad & 0,00 & $-1,68$ & 0,09 & $-0,01$ & 0,00 & 39,7 & & \multirow{4}{*}{0,548} \\
\hline aedu & $-0,02$ & 0,01 & $-2,06$ & 0,04 & $-0,04$ & 0,00 & 17,50 & \\
\hline est & 0,10 & 0,03 & 3,63 & 0,00 & 0,05 & 0,16 & 5,00 & \\
\hline ing & 0,00 & 0,00 & 1,85 & 0,07 & 0,00 & 0,00 & 2800000 & \\
\hline edad & 0,00 & 0,00 & $-1,66$ & 0,10 & $-0,01$ & 0,00 & 47 & \multirow{4}{*}{0,619} \\
\hline aedu & $-0,02$ & 0,01 & $-2,02$ & 0,04 & $-0,04$ & 0,00 & 19,2 & \\
\hline est & 0,10 & 0,02 & 4,10 & 0,00 & 0,05 & 0,15 & 6,00 & \\
\hline ing & 0,00 & 0,00 & 1,83 & 0,07 & 0,00 & 0,00 & 3400000 & \\
\hline
\end{tabular}

Fuente: Elaboración propia 
Andrés Mauricio Gómez Sánchez

Fuga de demanda en el sector comercial de Popayán, Colombia: una aproximación con modelos Logit

Anexo 3. Resultados Totales Probabilidad de Compra Frecuente por Tipo de Bien o Servicio

\begin{tabular}{|c|c|c|c|c|c|c|}
\hline & Robust & & & & & \\
\hline ele & Coef. & Std. Err. & $z$ & $P>z$ & [95\% Conf. & Interval] \\
\hline aedu & $-0,08$ & 0,04 & $-2,14$ & 0,03 & $-0,16$ & $-0,01$ \\
\hline est & 0,22 & 0,12 & 1,76 & 0,08 & $-0,03$ & 0,46 \\
\hline ing & 0,00 & 0,00 & 2,38 & 0,02 & 0,00 & 0,00 \\
\hline _cons & $-0,67$ & 0,54 & $-1,25$ & 0,21 & $-1,72$ & 0,38 \\
\hline gen & $-1,07$ & 0,29 & $-3,66$ & 0,00 & $-1,64$ & $-0,50$ \\
\hline est & 0,40 & 0,14 & 2,87 & 0,00 & 0,13 & 0,67 \\
\hline _cons & 0,91 & 0,46 & 1,98 & 0,05 & 0,01 & 1,81 \\
\hline est & 0,28 & 0,11 & 2,64 & 0,01 & 0,07 & 0,49 \\
\hline _cons & $-1,46$ & 0,39 & $-3,78$ & 0,00 & $-2,21$ & $-0,70$ \\
\hline gen & $-0,75$ & 0,38 & $-1,97$ & 0,05 & $-1,49$ & 0,00 \\
\hline edad & 0,04 & 0,01 & 2,80 & 0,01 & 0,01 & 0,07 \\
\hline ing & 0,00 & 0,00 & 2,35 & 0,02 & 0,00 & 0,00 \\
\hline _cons & $-4,18$ & 0,66 & $-6,38$ & 0,00 & $-5,46$ & $-2,90$ \\
\hline ing & 0,00 & 0,00 & 2,73 & 0,01 & 0,00 & 0,00 \\
\hline _cons & $-4,27$ & 0,64 & $-6,65$ & 0,00 & $-5,53$ & $-3,01$ \\
\hline edad & 0,02 & 0,01 & 2,04 & 0,04 & 0,00 & 0,04 \\
\hline ing & 0,00 & 0,00 & 4,63 & 0,00 & 0,00 & 0,00 \\
\hline _cons & $-4,21$ & 0,56 & $-7,45$ & 0,00 & $-5,31$ & $-3,10$ \\
\hline aedu & 0,18 & 0,05 & 3,51 & 0,00 & 0,08 & 0,27 \\
\hline est & 0,22 & 0,14 & 1,63 & 0,10 & $-0,04$ & 0,49 \\
\hline ing & 0,00 & 0,00 & 2,28 & 0,02 & 0,00 & 0,00 \\
\hline _cons & $-5,33$ & 0,82 & $-6,52$ & 0,00 & $-6,93$ & $-3,73$ \\
\hline aedu & $-0,15$ & 0,05 & $-3,19$ & 0,00 & $-0,23$ & $-0,06$ \\
\hline _cons & 0,31 & 0,68 & 0,45 & 0,65 & $-1,03$ & 1,64 \\
\hline
\end{tabular}




\begin{tabular}{|l|c|c|c|c|c|c|c|c|}
\hline Variable & $\mathbf{d y} / \mathbf{d x}$ & Std. Err & $\mathbf{z}$ & $\mathrm{P}>|\mathbf{z}|$ & \multicolumn{2}{|c|}{$95 \% \mathbf{I . C}$} & $\mathbf{X}$ & $\mathrm{Pr}$ \\
\hline aedu & $-0,02$ & 0,01 & $-2,16$ & 0,03 & $-0,03$ & 0,00 & 15,74 & \\
\hline est & 0,05 & 0,03 & 1,81 & 0,07 & 0,00 & 0,10 & 3,00 & $\mathbf{0 , 3 2}$ \\
\hline ing & 0,00 & 0,00 & 2,35 & 0,02 & 0,00 & 0,00 & 2000000 & \\
\hline gen* & $-0,15$ & 0,04 & $-3,68$ & 0,00 & $-0,24$ & $-0,07$ & 0,00 & \\
\hline est & 0,04 & 0,01 & 2,64 & 0,01 & 0,01 & 0,07 & 3,00 & $\mathbf{0 , 8 9}$ \\
\hline est & 0,06 & 0,02 & 2,74 & 0,01 & 0,02 & 0,11 & 3,00 & $\mathbf{0 , 3 5}$ \\
\hline gen* & $-0,06$ & 0,03 & $-2,17$ & 0,03 & $-0,11$ & $-0,01$ & 0,00 & \\
\hline edad & 0,00 & 0,00 & 2,82 & 0,01 & 0,00 & 0,01 & 36,20 & $\mathbf{0 , 1 2}$ \\
\hline ing & 0,00 & 0,00 & 2,25 & 0,03 & 0,00 & 0,00 & 2000000 & \\
\hline ing & 0,00 & 0,00 & 3,30 & 0,00 & 0,00 & 0,00 & 2000000 & $\mathbf{0 , 0 4}$ \\
\hline edad & 0,00 & 0,00 & 2,05 & 0,04 & 0,00 & 0,00 & 36,20 & $\mathbf{0 , 1 0}$ \\
\hline ing & 0,00 & 0,00 & 5,05 & 0,00 & 0,00 & 0,00 & 2000000 & \\
\hline aedu & 0,03 & 0,01 & 3,59 & 0,00 & 0,01 & 0,05 & 15,74 & $\mathbf{0 , 2 1}$ \\
\hline est & 0,04 & 0,02 & 1,70 & 0,09 & $-0,01$ & 0,08 & 3,00 & \\
\hline ing & 0,00 & 0,00 & 2,23 & 0,03 & 0,00 & 0,00 & 2000000 & \\
\hline aedu & $-0,02$ & 0,00 & $-3,37$ & 0,00 & $-0,02$ & $-0,01$ & 15,74 & $\mathbf{0 , 1 2}$ \\
\hline
\end{tabular}

Fuente: Elaboración propia 
Andrés Mauricio Gómez Sánchez

Fuga de demanda en el sector comercial de Popayán, Colombia: una aproximación con modelos Logit

Anexo 4. Modelo Logit de Compra por Motivo

\begin{tabular}{|l|c|c|c|c|c|c|}
\hline \multicolumn{1}{|c|}{ precio } & Coef. & Std. Err. & $\mathbf{z}$ & $\mathbf{P}>\mathbf{z}$ & Conf. & Interval] \\
\hline edad & $-0,02$ & 0,01 & $-2,32$ & 0,02 & $-0,04$ & 0,00 \\
\hline _cons & 1,38 & 0,35 & 3,94 & 0,00 & 0,69 & 2,06 \\
\hline ing & 0,00 & 0,00 & $-0,99$ & 0,32 & 0,00 & 0,00 \\
\hline _cons & $-0,48$ & 0,22 & $-2,23$ & 0,03 & $-0,91$ & $-0,06$ \\
\hline gen & $-0,57$ & 0,23 & $-2,51$ & 0,01 & $-1,02$ & $-0,13$ \\
\hline aedu & 0,15 & 0,04 & 4,26 & 0,00 & 0,08 & 0,23 \\
\hline cons & $-1,39$ & 0,56 & $-2,48$ & 0,01 & $-2,50$ & $-0,29$ \\
\hline aedu & $-0,09$ & 0,05 & $-1,73$ & 0,08 & $-0,19$ & 0,01 \\
\hline cons & $-0,89$ & 0,78 & $-1,14$ & 0,25 & $-2,42$ & 0,64 \\
\hline aedu & 0,05 & 0,03 & 1,44 & 0,15 & $-0,02$ & 0,12 \\
\hline cons & $-1,26$ & 0,56 & $-2,25$ & 0,02 & $-2,36$ & $-0,16$ \\
\hline gen & $-0,50$ & 0,24 & $-2,07$ & 0,04 & $-0,98$ & $-0,03$ \\
\hline aedu & 0,08 & 0,04 & 1,87 & 0,06 & 0,00 & 0,16 \\
\hline est & 0,21 & 0,11 & 1,87 & 0,06 & $-0,01$ & 0,43 \\
\hline cons & $-2,76$ & 0,67 & $-4,12$ & 0,00 & $-4,07$ & $-1,45$ \\
\hline edad & 0,04 & 0,01 & 3,21 & 0,00 & 0,02 & 0,07 \\
\hline _cons & $-3,96$ & 0,54 & $-7,31$ & 0,00 & $-5,02$ & $-2,90$ \\
\hline
\end{tabular}

\begin{tabular}{|l|c|c|c|c|c|c|c|c|}
\hline Variable & dy/dx & Std. Err. & $\mathbf{z}$ & $\mathbf{P}>\mathbf{z}$ & {$[\mathbf{9 5 \%}$} & C.I. ] & $\mathbf{X}$ & $\mathbf{P r}$ \\
\hline edad & 0,00 & 0,00 & $-2,32$ & 0,02 & $-0,01$ & 0,00 & 36,20 & $\mathbf{0 , 6 5}$ \\
\hline ing & 0,00 & 0,00 & $-0,99$ & 0,32 & 0,00 & 0,00 & 2000000 & $\mathbf{0 , 3 4}$ \\
\hline gen* & $-0,12$ & 0,05 & $-2,52$ & 0,01 & $-0,22$ & $-0,03$ & 0,00 & \\
\hline aedu & 0,03 & 0,01 & 4,30 & 0,00 & 0,02 & 0,04 & 15,74 & $\mathbf{0 , 7 4}$ \\
\hline aedu & $-0,01$ & 0,00 & $-1,77$ & 0,08 & $-0,02$ & 0,00 & 15,75 & $\mathbf{0 , 0 9}$ \\
\hline aedu & 0,01 & 0,01 & 1,44 & 0,15 & 0,00 & 0,03 & 15,75 & $\mathbf{0 , 3 8}$ \\
\hline gen* & $-0,09$ & 0,04 & $-2,13$ & 0,03 & $-0,18$ & $-0,01$ & 0,00 & \\
\hline aedu & 0,02 & 0,01 & 1,85 & 0,06 & 0,00 & 0,03 & 15,74 & $\mathbf{0 , 2 9}$ \\
\hline est & 0,04 & 0,02 & 1,91 & 0,06 & 0,00 & 0,09 & 3,00 & \\
\hline edad & 0,00 & 0,00 & 3,22 & 0,00 & 0,00 & 0,00 & 36,20 & $\mathbf{0 , 0 8}$ \\
\hline
\end{tabular}

Fuente: Elaboración propia 